\title{
Pengaruh Harga Dan Celebrity Endorser Terhadap Minat Beli Shampo Clear (Studi Kasus Pada Mahasiswa Universitas Sari Mutiara Indonesia)
}

\author{
Roberto Roy Purba ${ }^{1}$, Feni Wati ${ }^{2}$ \\ ${ }^{12}$ Program Studi Manajemen Universitas Sari Mutiara Indonesia \\ robertoroypurba@gmail.com, ${ }^{2}$ feniwati0508@gmail.com
}

\begin{abstract}
Advertising through celebrity endorsers is currently in great demand to introduce and promote products to the public. The use ofadvertisements is celebrity endorser considered effective to increase product sales, this is because the development of very fast information flow is supported by the existence of technology that makes consumers able to absorb information and knowledgeabout a product quickly. Likewise with pricing strategies that can affect consumerbuying interest. This study aims to determine the effect of price on interest in buying shampoo clear to the students of the Sari Mutiara Indonesia University, celebrity endorser on interest in buying shampoo clear to the students of the Sari Mutiara Indonesia University and celebrity endorser on interest in buying shampoo clear to the students of the Sari Mutiara Indonesia University. This research was conducted using a quantitative descriptive method by distributing questionnaires to 100 student respondents atthe Sari Mutiara Indonesia University which were analyzed by multiple linear regression, the sampling technique was using Non-Probability Sampling.The results of this study indicate that the price variable (X1) has a significant positive effect on the buying interest variable $(Y)$ while thevariable celebrity endorser $(X 2)$ has a significant positive effect on the buying interest variable (Y). It can be concluded that the influence of each variable simultaneously can be seen that $F_{\text {hitung }}(117.184)>F_{\text {table }}$ (3.09) or sig. of $0.000<0.05$. The data were statistically processed using SPSS 25 program tools.
\end{abstract}

Keywords: Price; Celebrity Endorser; Buying Interest

\begin{abstract}
Abstrak
Iklan melalui celebrity endorser saat ini banyak diminati untuk memperkenalkan danmempromosikan produk kepada masyarakat. Penggunaan iklan celebrity endorser dianggap efektif untuk meningkatkan penjualan produk hal ini dikarenakan perkembangan arus informasi yang sangat cepat ditunjang dengan keberadaan teknologi membuat konsumen dapat menyerap informasi serta pengetahuan tentang suatu produk dengan cepat. Begitu pula dengan strategi penetapan harga yang dapat mempengaruhi minat beli konsumen. Penelitian ini bertujuan untuk mengetahui pengaruh harga terhadap minat beli shampo Clear padamahasiswa Universitas Sari Mutiara Indonesia, pengaruh celebrity endorser terhadap terhadap minat beli shampo Clear pada mahasiswa Universitas Sari Mutiara Indonesia, dan pengaruh harga dan celebrity endorser terhadap minat beli shampo Clear padamahasiswa Universitas Sari Mutiara Indonesia. Penelitian ini dilakukan dengan metode deskriptif kuantitatif dengan membagikan kuesioner kepada 100 responden mahasiswa Universitas Sari Mutiara Indonesia yang dianalisis dengan regresi linear berganda, teknik pengambilan sampel yaitu dengan menggunakan Non probability Sampling. Hasil penelitian ini menunjukkan bahwa variabel harga (X1) berpengaruh positif signifikan terhadap variabel minat beli (Y) sedangkan variabel celebrity endorser (X2) berpengaruh positif signifikan terhadap
\end{abstract}


variabel minat beli (Y).Dapat disimpulkan bahwa pengaruh dari setiap variabel secara simultan dapat dilihat bahwa nilai nilai $\mathrm{F}_{\text {hitung }}(117,184)>\mathrm{F}_{\text {tabel }}(3,09)$ atau sig. sebesar $0,000<0,05$. Data diolah secara statistik dengan menggunakan alat bantu program SPSS 25.

Kata Kunci: Harga; Celebrity Endorser; Minat Beli

\section{Pendahuluan}

Dalam persaingan dunia bisnis yang sudah semakin ketat, menyebabkan setiap perusahaan berlomba-lomba demi mencapai keunggulan kompetitif untuk memperebutkan pangsa pasar. Ditambah dengan tegnologi yang semakin canggih membuat konsumen dapat menyerap informasi tentang suatu barang dengan cepat dan perusahaan harus tanggap dengan apa yang diinginkan oleh konsumen, memberikan informasi mengenai produknya secara tepat sehingga konsumen akan memberikan timbal balik yang positif terhadap hal tersebut (Sukma, Nurcahya \& Suryani, 2016).

Salah satu industri yang mengalami persaingan ketat saat ini adalah industri shampo. Shampo sudah menjadi kebutuhan sehari-hari di dalam kehidupan manusia khususnya mahasiswa Universitas Sari Mutiara Indonesia yang pada saat ini semakin banyak terpengaruh dengan jenis dan merek shampo yang beredar dipasaran. Pemilihan shampo yang tidak tepat dapat menyebabkan gangguan pada kesehatan rambut, seperti rambut menjadi kering, rambut berketombe, rambut bercabang, gatal-gatal dan lain-lain. Setelah melaksanakan survei kepada mahasiswa Universitas Sari Mutiara Indonesia, maka pemilihan penggunaan shampo lebih cenderung dengan iklan yang dibawakan oleh celebrity endorser. Konsumen akan menggunakan produk shampo yang menurut persepsinya terbaik (Pakaya \& Tumbuan, 2017). Produsen shampo di Indonesia di kuasai oleh dua perusahaan yang sudah di kenal namanya yaitu PT. Unilever Tbk dan PT. Procter \& Gamble (Suhardi \& Irmayanti, 2019).

Salah satu faktor yang menyebabkan kinerja luar biasa Clear adalah mempunyai slogan yaitu "ketombe? Siapa takut!" merupakan jawaban yang dibutuhkan masyarakat indonesia karena iklim tropis Indonesia yang dapat menyebabkan kelembaban serta mengurangi rasa percaya diri sehingga membuat ketombe menjadi masalah umum masyarakat Indonesia. Clear konsisten dengan persoalan ketombe dan selalu melakukan inovasi pada produknya agar selalu cocok dengan pasar yang dituju. Dengan adanya slogan shampo clear itu memberikan nilai positif dalam mempengaruhi minat beli ulang konsumen.

Sekian banyak merek shampo yang ada di pasaran, minat beli konsumen dipengaruhi oleh beberapa faktor diantaranya adalah harga (Pakaya \& Tumbuan, 2017). Harga memiliki peranan yang sangat penting dalam mempengaruhi konsumen dalam meningkatkan minat beli konsumen. Menurut Sumarwan dalam (Roberto Roy, 2019) harga adalah unsur yang dipergunakan untuk bauran pemasaran yang di bisa di kontrol oleh institusi.

Untuk harga shampo Clear sendiri mengalami perubahan penurunan dan kenaikan harga dari tahun ke tahun yang mana membuat mahasiswa mempertimbangkan kembali membeli shampo Clear. Harga yang murah menjadi pertimbangan mahasiswa untuk memilih produk shampo Clear apabila kinerja shampo Clear sama dengan produk yang lebih mahal. Berikut beberapa shampo Clear yang mengalami perubahan harga: 
Tabel 1. Data Harga Shampo Clear

\begin{tabular}{|l|c|c|c|c|}
\hline \multicolumn{1}{|c|}{ Nama Produk } & Isi & $\mathbf{2 0 1 9}$ & $\mathbf{2 0 2 0}$ & $\mathbf{2 0 2 1}$ \\
\hline $\begin{array}{l}\text { Clear shampo anti dundruf } \\
\text { complete soft care }\end{array}$ & $80 \mathrm{ml}$ & 10.200 & 12.000 & 11.550 \\
\hline $\begin{array}{l}\text { Clear men cool sport menthol anti } \\
\text { dundruf shampo }\end{array}$ & $160 \mathrm{ml}$ & 19.500 & 20.590 & 17.999 \\
\hline $\begin{array}{l}\text { Clear shampo anti dundruff ice } \\
\text { cool menthol }\end{array}$ & $320 \mathrm{ml}$ & 39.900 & 32.000 & 48.900 \\
\hline Clear shampo super fresh apple & $160 \mathrm{ml}$ & 19.600 & 22.890 & 27.000 \\
\hline
\end{tabular}

Sumber: www.priceprice.com

Ketika konsumen memiliki informasi yang akurat mengenai suatu produk maka mereka dapat membandingkan dan mencocokan produk yang satu dengan produk sejenisnya dan memilih produk mana yang dapat memberi kepuasan lebih. Harga bisa mempengaruhi minat beli disebabkan kemampuan konsumen melakukan pembelian dengan membandingkan khasiat yang hendak konsumen dapat dengan pengorbanan yang dikeluarkan sangatlah diperhatikan.

Tabel 2. Perbandingan Harga shampo Clear dan Pantene

\begin{tabular}{|l|c|c|}
\hline \multicolumn{1}{|c|}{ Nama Produk } & Isi & Harga \\
\hline Shampo Clear & $80 \mathrm{ml}$ & Rp. 11.550 \\
\hline $\begin{array}{l}\text { Clear shampo anti dundruf complete } \\
\text { soft care }\end{array}$ & $160 \mathrm{ml}$ & Rp. 17.999 \\
\hline $\begin{array}{l}\text { Clear men cool sport menthol antidundruf } \\
\text { shampo }\end{array}$ & $160 \mathrm{ml}$ & Rp. 27.000 \\
\hline $\begin{array}{l}\text { Clear shampo anti dundruf natural } \\
\text { black }\end{array}$ & $160 \mathrm{ml}$ & Rp. 26.200 \\
\hline $\begin{array}{l}\text { Clear shampo anti dundruff ice cool } \\
\text { menthol }\end{array}$ & $170 \mathrm{ml}$ & Rp. 22.000 \\
\hline Clear shampo super fresh apple & $320 \mathrm{ml}$ & Rp. 32.000 \\
\hline $\begin{array}{l}\text { Clear hijab pure anti ketombe dan antirontok } \\
\text { shampo }\end{array}$ & $160 \mathrm{ml}$ & Rp. 31.900 \\
\hline Shampo Pantene & $160 \mathrm{ml}$ & Rp. 27.400 \\
\hline Pantene Shampo Hair Fall Control & $160 \mathrm{ml}$ & Rp. 22.200 \\
\hline Pantene shampo anti dundruf & $170 \mathrm{ml}$ & Rp. 40.000 \\
\hline Pantene shampo Daily Moisture & $135 \mathrm{ml}$ & Rp. 26.500 \\
\hline Pantene Shampoo Pro-v Silky smooth & $\begin{array}{l}\text { Pantene Hijab Edition Pro-v Anti } \\
\text { Ketombe }\end{array}$ & \\
\hline Sumber: Olahan Prapentian & & \\
\hline
\end{tabular}

Sumber: Olahan Prapenelitian

Dari tabel diatas Shampo Clear dan shampo Pantene tersedia dalam kemasan botol dengan ukuran yang berbeda-beda dan juga dalam kemasan sachet dengan harga yang cukup bersaing. Untuk harganya sendiri shampo Clear menetapkan harga sesuai dengan ukuran produk, semakin besar ukuran produknya maka semakin mahal harganya begitu juga sebaliknya. Mahasiswa merupakan konsumen yang potensial karna banyaknya kegiatan yang dilakukan seorang mahasiswa membuat mereka selektif dalam memilih 
shampo yang sesuai dengan rambut mereka. Oleh karena itu, shampo Clear menawarkan beberapa varian produk dengan masing-masing kelebihan dan kualitasnya yang sesuai yang dibutuhkan oleh konsumen. Untuk harga shampo Clear dikalangan mahasiswa masih dapat dijangkau dibandingkan dengan shampo Pantene yang sedikit lebih mahal sehingga mempengaruhi minat beli shampo Clear.

Di dalam mengiklankan produk sering kali menggunakan dukungan kaum selebriti dan juga non selebriti agar keberadaan produk yang baru dapat diketahui oleh masyarakat (Fransisca, 2018) serta dalam rangka meremajakan kembali produk ataupun merek yang telah loyo, tidak sedikit perusahaan terpikat untuk menggunakan selebriti. Pemakaian selebriti pendukung (celebrity endorser) sekalian bisa melaksanakan pembeda dengan produk-produk kompetitor yang terdapat dipasar. Basis pembeda ini sangat penting karna dapat digunakan konsumen untuk memilih dari berbagai macam produk yang ditawarkan produsen dan tetap mempertahankan eksistensi produk di pasar.

Memanfaatkan artis pendukung (celebrity endorser) juga dilakukan PT. Unilever tbk dengan menggandeng sebagian artis salah satunya Agnes Monica sebab prestasinya yang sanggup menginspirasi generasi muda Indonesia dan rambut agnes yang sehat serta bebas ketombe. Setelah itu pula disebabkan gaya Agnes yang unik bisa memenuhi Agnes selaku personifikasi dari seluruh value yang diusung Clear ialah Musik, gaya, serta terobosan (www.detik.com).

Kotler dan Keller (Alkatiri, Tumbel, \& Roring, 2017) menyatakan bahwa minat beli konsumen merupakan sebuah perilaku konsumen dimana konsumen mempunyai keinginan dalam memilih, menggunakan, dan mengkonsumsi atau bahkan menginginkan suatu produk yang di tawarkan. Salah satu indikator bahwa suatu produk sukses atau tidak di pasar adalah seberapa jauh tumbuhnya minat beli konsumen terhadap produk tersebut.

Tabel 3. Hasil Kuisioner Pra-Survey tingkat Minat Beli shampo Clear

\begin{tabular}{|c|c|c|c|c|}
\hline \multirow{2}{*}{ No } & \multirow{2}{*}{ Pertanyaan } & \multicolumn{2}{|c|}{ Jawaban } & \multirow{2}{*}{$\begin{array}{c}\text { Jumlah } \\
\text { responden }\end{array}$} \\
\hline & & Ya & Tidak & \\
\hline 1. & $\begin{array}{l}\text { Apakah anda pernah menggunakan } \\
\text { shampo Clear? }\end{array}$ & 18 & 2 & 20 \\
\hline 2. & $\begin{array}{l}\text { Apakah sampai sekarang anda masih } \\
\text { menggunakan shampo Clear? }\end{array}$ & 8 & 12 & 20 \\
\hline 3. & $\begin{array}{l}\text { Apakah menurut anda harga shampo } \\
\text { Clear terjangkau? }\end{array}$ & 13 & 7 & 20 \\
\hline 4. & $\begin{array}{l}\text { Apakah anda mengenal celebrity } \\
\text { Endorser (Agnes Monika) pada iklan } \\
\text { shampo Clear? }\end{array}$ & 20 & - & 20 \\
\hline 5. & $\begin{array}{l}\text { Apakah iklan shampo Clear menjadi } \\
\text { menarik karena dibawakan oleh Agnes } \\
\text { monika yang terkenal? }\end{array}$ & 19 & 1 & 20 \\
\hline 6. & $\begin{array}{l}\text { Apakah menurut anda informasi yang } \\
\text { disampaikan Agnes Monika mengenai } \\
\text { shampo Clear jelas? }\end{array}$ & 16 & 4 & 20 \\
\hline
\end{tabular}

Hasil prasurvey yang dilakukan terhadap 20 responden mahasiswa Universitas Sari Mutiara Indonesia. 2 responden mahasiswa mengatakan tidak pernah menggunakan shampo Clear, 13 responden yang mengatakan mereka cenderung menggunakan shampo Clear karna harga shampo Clear yang dapat dijangkau, menyukai baik dari model endorser maupun fungsi dari shampo itu sendiri namun setelah penggunaan shampo Clear itu membuat kulit kepala mahasiswa semakin berketombe, rambut gatal, yang mana mahasiswa tidak merasakan manfaat dari produk shampo Clear yang digunakan. Sehingga 
membuat Mahasiswa tidak ingin mencoba produk shampo Clear lainnya yang mungkin saja cocok dengan kulit kepala mereka. Informasi yang disampaikan oleh Agnes Monika mengenai shampo Clear tidak jelas informasinya menurut 4 responden mahasiswa, ini dikarenakan informasi yang diberikan terlalu singkat yang membuat mahasiswa merasa tidak yakin tentang produk tersebut.

\section{Metode}

Penelitian ini dilaksanakan di Universitas Sari Mutiara Indonesia dan waktu Penelitiandilaksanakan di bulan Mei 2021 sampai dengan bulan Juli 2021. Universitas Sari Mutiara Indonesia. Populasi adalah wilayah generalisasi yangterdiri atas: obyek/subjek yang mempunyai kualitas dan karakteristik tertentu yang ditetapkan oleh peneliti untuk dipelajari dan kemudian ditarik kesimpulannya (Sugiyono, 2017). Berdasarkan pengertian populasi diatas maka populasi dalam penelitian ini adalah mahasiswa pengguna shampo Clear di Universitas Sari MutiaraIndonesia dengan sampel yang berjumlah 100 sampel dengan rancangan sampel Non probability Sampling dengan teknik pengambilan Purposive sampling. Teknik pengumpulan data menggunakan kuesioner. Uji validitas merupakan ukuran yang menunjukan sejauh mana instrumen yang digunakan untuk mengukur apa yang seharusnya diukur (Sugiyono, 2014). Reliabilitas adalah instrumen yang bila digunakan beberapa kali untuk mengukur obyek yang sama, akan menghasilkan data yang sama. untuk mengukur reliabilitas adalah Cronbach Alpha. Suatu variabel dikatakan reliabel, apabila hasil CronbachAlpha $>0,60=$ reliabel. Hasil Cronbach Alpha $<0,60$ maka tidak reliable. Uji asumsi klasik dilakukan dalam upaya untuk memperoleh hasil analisa regresi yang sahid (valid).

\section{Hasil Dan Pembahasan}

1. Analisis Deskriptif Responden

a. Berdasarkan Jenis Kelamin

Tabel 4. Karakteristik Responden Berdasarkan Jenis Kelamin

\begin{tabular}{|l|l|l|}
\hline $\begin{array}{c}\text { Jenis } \\
\text { Kelamin }\end{array}$ & Jumlah & Persentase \\
\hline Laki-laki & 28 & $28 \%$ \\
\hline Perempuan & 72 & $72 \%$ \\
\hline Total & 100 & $100 \%$ \\
\hline
\end{tabular}

Sumber: olah data primer, (2021)

Berdasarkan karakteristik jenis kelamin tabel 4 menunjukkan bahwa dari 100 orang responden, terlihat bahwa responden laki-laki sebanyak 28 orang dengan persentase sebesar $28 \%$ dan responden perempuan yaitu sebanyak 72 orang dengan persentase $72 \%$. Mahasiswa yang berjenis kelamin perempuan merupakan responden dengan jumlah terbanyak pada penelitian ini responden perempuan lebih banyak yang melihat iklan shampo Clear mengingat perempuan lebih mementingkan kesehatandan rambut yang halus.

b. Berdasarkan Tahun Masuk Kuliah

Tabel 5. Karakteristik Responden BerdasarkanTahun Masuk Kuliah

\begin{tabular}{|l|l|l|}
\hline $\begin{array}{c}\text { Tahun } \\
\text { Masuk }\end{array}$ & \multicolumn{1}{|c|}{ Jumlah } & \multicolumn{1}{|c|}{ Persentase } \\
\hline 2020 & 4 & $4 \%$ \\
\hline 2019 & 34 & $34 \%$ \\
\hline 2018 & 20 & $20 \%$ \\
\hline
\end{tabular}




\begin{tabular}{|l|l|l|}
\hline 2017 & 42 & $42 \%$ \\
\hline Total & 100 & $100 \%$ \\
\hline
\end{tabular}

Sumber: olah data primer, (2021)

Tabel 5 menunjukan bahwa dari 100 responden, 4 orang (4\%) merupakan mahasiswa tahun masuk 2020, 34 orang (34\%) merupakan mahasiswa tahun masuk 2019, 20 orang $(20 \%)$ merupakan mahasiswa tahun masuk 2018, 42 orang (42\%) merupakan mahasiswa tahun masuk 2017 dan merupakan responden denganjumlah terbanyak pada penelitian ini.

c. Berdasarkan Fakultas

Tabel 6. Karakteristik Responden Berdasarkan Fakultas

\begin{tabular}{|l|l|l|}
\hline Fakultas Iumlah & Persentase \\
\hline $\begin{array}{l}\text { Fakultas Farmasi } \\
\text { dan Ilmu } \\
\text { Kesehatan } \\
\text { (FIKES) }\end{array}$ & 32 & $32 \%$ \\
\hline $\begin{array}{l}\text { Fakultas Ekonomi } \\
\text { dan Ilmu Sosial } \\
\text { (FEIS) }\end{array}$ & 50 & $50 \%$ \\
\hline $\begin{array}{l}\text { Fakultas Sain dan } \\
\text { Tegnologi } \\
\begin{array}{l}\text { Tanformasi } \\
\text { Informan } \\
\text { (F.SAINTI) }\end{array}\end{array}$ & 15 & $15 \%$ \\
\hline $\begin{array}{l}\text { Fakultas Ilmu } \\
\text { Pendidikan (FIP) }\end{array}$ & 3 & $3 \%$ \\
\hline Total & 100 & $100 \%$ \\
\hline
\end{tabular}

Sumber: olah data primer, (2021)

Tabel 6 menunjukan bahwa dari 100 responden, 32 orang (32\%) merupakan mahasiswa FIKES, 50 orang (50\%) merupakan mahasiswa FEIS, 15 orang (15\%) merupakan mahasiswa F.SAINTI, 3 orang (3\%) merupakan mahasiswa FIP,Responden dengan jumlah terbanyak padapenelitian ini adalah mahasiswa FEIS.

\section{Uji Normalitas}

a. Uji Kolmonogorov-Smirnov

1) jika nilai signifikansi $>0,05$, maka nilairesidual berdistribusi normal.

2) jika nilai signifikansi $<0,05$, maka nilairesidual tidak berdistribusi normal.

Tabel 7. Uji Normalitas

\begin{tabular}{|c|c|c|}
\hline \multicolumn{3}{|c|}{ One-Sample Kolmogorov-Smirnov Test } \\
\hline & & $\begin{array}{l}\text { Unstandardized } \\
\text { Residual }\end{array}$ \\
\hline \multicolumn{2}{|l|}{$\mathrm{N}$} & 100 \\
\hline \multirow{2}{*}{$\begin{array}{l}\text { Normal } \\
\text { Parameters }{ }^{\mathrm{a}, \mathrm{b}}\end{array}$} & Mean & .0000000 \\
\hline & \begin{tabular}{|l} 
Std. \\
Deviation
\end{tabular} & 3.30898537 \\
\hline \multirow{3}{*}{$\begin{array}{l}\text { Most Extreme } \\
\text { Differences }\end{array}$} & Absolute & .073 \\
\hline & Positive & .033 \\
\hline & Negative & -.073 \\
\hline \multicolumn{2}{|l|}{ Test Statistic } & .073 \\
\hline
\end{tabular}




\begin{tabular}{|l|l|}
\hline Asymp. Sig. (2-tailed) & .200 \\
\hline
\end{tabular}

\section{Sumber: Hasil Olah Data SPSS 25}

Berdasarkan hasil pengolahan data pada tabel 7 diperoleh besarnya Kolmonogorov-Smirnov adalah 0,200. Nilai signifikansi lebih besar dari 0,05, maka dapat dikatakan bahwa nilai residual berdistribusi normal.

b. Grafik Histogram

Berikut ini dapat diketahui bahwa databerdistribusi normal, hal tersebut dapat dilihat dari grafik histogram yang berbentuk lonceng, grafik tersebut tidak miring kesamping kiri maupun kanan seperti terlihat pada gambar berikut:

Gambar 1. Histogram Uji Normalitas

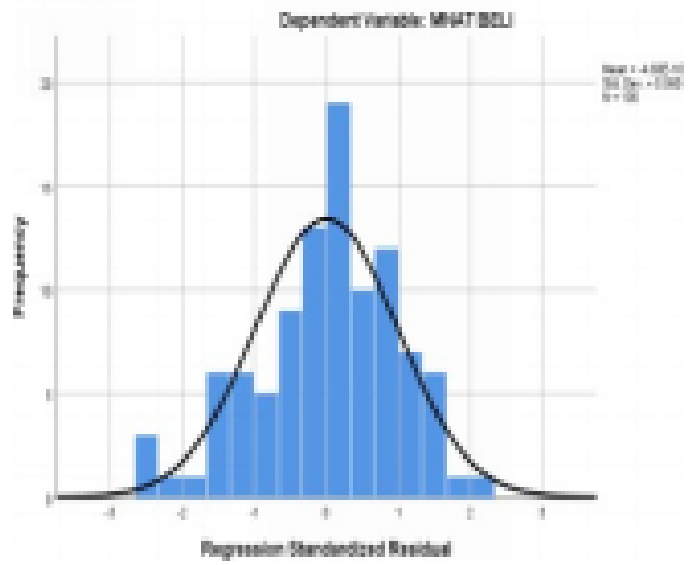

Sumber: Hasil Olah Data SPSS 25

Berdasarkan gambar 1 dapat dilihat bahwa data tersebut berdistribusi normal. Hal ini ditunjukkan oleh distribusi data pada grafik histogram tersebut dengan bentuk lonceng. c. Grafik P-P plot

Pendekatan ini dilakukan dengan melihat titik-titik yang tersebar di sepanjang garis diagonal dan mengikuti arah garis diagonal, maka data berdistribusi normal.

Gambar 2. Grafik Uji Normalitas

Normal P-Plot of Regression StandardizedResidual

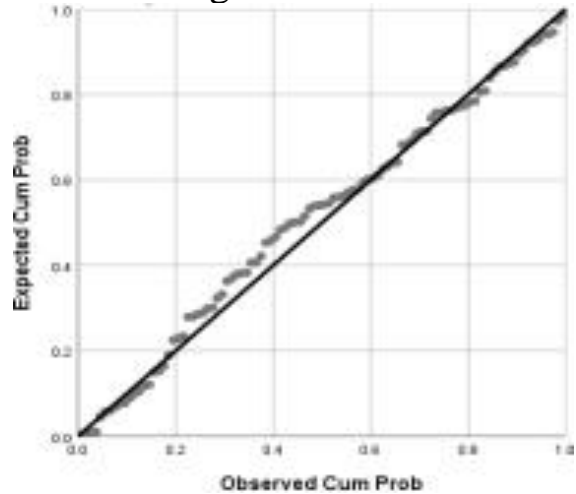

Sumber: Hasil Olah Data SPSS 25

Berdasarkan pada gambar 2 bahwa dapat dilihat data menyebar disekitar garis diagonal mengikuti arah garis diagonal. Hal ini berarti data berdistribusi normal.

Tabel 8. Uji Multikolinearitas

\begin{tabular}{|l|l|}
\hline Tolerance & VIF \\
\hline 452 & 2.214 \\
\hline
\end{tabular}

Berdasarkan tabel diatas dapat diketahui bahwa nilai tolerance pada variabel Harga $\left(\mathrm{X}_{1}\right)$ dan Celebrity Endorser $\left(\mathrm{X}_{2}\right)$ sebesar0,452 > 0,10. Sedangkan nilai VIF untukvariabel 
Harga $\left(\mathrm{X}_{1}\right)$ dan Celebrity Endorser $\left(\mathrm{X}_{2}\right)$ sebesar $2.214<10$. Mengacu pada dasar pengambilan keputusan, dapat di simpulkan bahwa tidak terjadi gejala multikolinearitas dalam model regresi.

\section{Uji Heteroskedastisitas}

Gambar 3. Uji Heteroskedastisitas

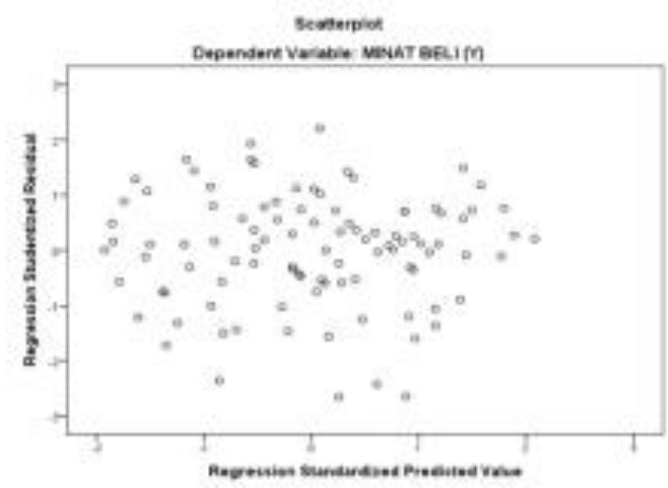

Sumber: Hasil Olah Data SPSS 25

Berdasarkan gambar bahwa grafik scatterplot yang disajikan pada gambar diatas dapat dilihat titik-titik menyebar secara acak tidak membentuk pola tertentu yang jelas serta tersebar baik di atas maupundi bawah angka nol pada sumbu Y. hal ini berarti tidak terjadi heteroskedastisitas pada model regresi, sehingga model regresi dapat dipakai untuk memprediksikan minat beli berdasarkan masukan variabelindependennya.

\section{Hasil Analisis Regresi Berganda}

$\mathrm{Y}=7.974+0,605 \mathrm{X}_{1}+0,343 \mathrm{X}_{2}+\mathrm{e}$

Persamaan regresi berganda tersebut dijelaskan sebagai berikut :

a. Nilai konstanta sebesar 7.974, apabila variabel harga dan celebrity endorser dianggap nol, maka minat beli shampoo Clear pada mahasiswa Universitas SariMutiara Indonesia adalah sebesar 7.974.

b. Nilai koefisien harga (X1) sebesar 0,605 menyatakan bahwa setiap kenaikan harga makin baik maka minat beli (Y) akan mengalami kenaikan sebesar 0,605.

c. Nilai koefisien celebrity endorser (X2) sebesar 0,343 menyatakan bahwa setiap kenaikan celebrity endorser makin baik maka minat beli (Y) akan mengalami kenaikan sebesar 0,343.

\section{Uji Parsial (T)}

Tabel 9. Uji Parsial (Uji T)

\begin{tabular}{|c|c|c|c|c|c|c|}
\hline \multicolumn{7}{|c|}{ Coefficients" } \\
\hline \multirow{2}{*}{\multicolumn{2}{|c|}{ Modd }} & \multicolumn{2}{|c|}{$\begin{array}{l}\text { Unstandardized } \\
\text { Coefficients }\end{array}$} & \multirow{2}{*}{$\begin{array}{c}\begin{array}{c}\text { Standardized } \\
\text { Coefficients }\end{array} \\
\text { Beta }\end{array}$} & \multirow[b]{2}{*}{$t$} & \multirow[b]{2}{*}{ Sig } \\
\hline & & B & $\begin{array}{l}\text { Sod } \\
\text { Enor }\end{array}$ & & & \\
\hline \multirow[t]{3}{*}{1} & (Constant) & 7974 & 1.598 & & 4.989 & .000 \\
\hline & HARGA $(X 1)$ & 605 & .073 & 582 & 8.304 & .000 \\
\hline & $\begin{array}{l}\text { CELEBRITY ENDORSER } \\
\left(\mathrm{X} 2_{2}\right)\end{array}$ & 343 & .066 & 365 & 5.204 & .000 \\
\hline
\end{tabular}

Sumber: Hasil Olah Data Soffware Sratistic, 2021 
Berdasarkan tabel 9 dapat dilihat pengaruh dari setiap variabel secara parsial adalah sebagai berikut :

a. Hal ini dapat dilihat dari nilai signifikan variabel harga yaitu sig sebesar $0,000<0,05$ dan nilai t-hitung sebesar $8.304>\mathrm{t}$-tabel 1,985. maka H1 diterima.

b. Hal ini dapat dilihat dari nilai signifikan variabel celebrity endorser yaitu sig sebesar $0,000<0,05$ dan nilai t-hitung sebesar 5.204 t-tabel 1,985. maka $\mathrm{H} 2$ diterima.

\section{Uji Simultan (Uji F)}

Tabel 10. Uji Simultan (Uji F)

\begin{tabular}{|c|c|c|c|c|c|c|}
\hline \multicolumn{7}{|c|}{ ANOVA* } \\
\hline \multicolumn{2}{|c|}{ Model } & $\begin{array}{l}\text { Sum of } \\
\text { Segares }\end{array}$ & df & Mean Square & $\mathbf{F}$ & Siz \\
\hline \multirow[t]{3}{*}{1} & Regressian & 3960.121 & 2 & 1980060 & 177.184 & $000^{2}$ \\
\hline & Residual & 1083.989 & 97 & 11.175 & & \\
\hline & Total & 5044.110 & 99 & & & \\
\hline \multicolumn{7}{|c|}{ a. Dependent Vanible: Minat Beli (Y) } \\
\hline \multicolumn{7}{|c|}{ b. Prediclors: (Constant). Celebrity Endorser (X2), Harga (X1) } \\
\hline
\end{tabular}

Dari tabel 10 dapat diketahui bahwa $\mathrm{F}_{\text {hitung }}>\mathrm{F}_{\text {tabel }}$ yaitu $117,184>3,09$ dan nilai signifikan $=0,000<0,05$. Hal ini berartivariabel harga dan celebrity endorser secara bersama-sama berpengaruh positif dan signifikan terhadap minat beli shampo Clear pada mahasiswa Universitas Sari Mutiara Indonesia.

\section{Uji Koefisien Determinasi $\left(\mathbf{R}^{2}\right)$}

Tabel 11. Uji Koefisien Determinasi $\left(\mathrm{R}^{2}\right)$

\begin{tabular}{|c|c|c|c|}
\hline \multicolumn{4}{|c|}{ Model Summary } \\
\hline Mode & $\mathrm{R} \quad \mathrm{R} \mathrm{Sq}$ & $\begin{array}{l}\text { Adjusted } \\
\mathrm{r} \in \mathrm{R} \text { Square }\end{array}$ & $\begin{array}{l}\text { Std. Error of } \\
\text { theEstimate }\end{array}$ \\
\hline 1 & $.886^{\mathrm{a}} .785$ & .781 & 3.34292 \\
\hline
\end{tabular}

Sumber: Hasil Olah Data

Berdasarkan tabel 11 dapat dilihat bahwa nilai R square yaitu sebesar 0.785 atau $78,5 \%$, dimana nilai koefisien determinasiini menunjukan bahwa hubungan antaraharga dan celebrity endorser terhadap minat beli adalah kuat, sedangkan sisanya sebesar $21.5 \%$ dipengaruhi oleh variabel lain diluar penelitian ini.

\section{Pengaruh Harga Terhadap Minat Beli Shampo Clear.}

$\mathrm{H} 1=$ Harga berpengaruh terhadap minat beli shampo Clear pada mahasiswa Universitas Sari Mutiara Indonesia. Dari hasil pengujianhipotesis (H1) yang dilakukan peneliti terbukti bahwa harga yang diberikan olehshampo Clear memiliki pengaruh yang signifikan terhadap minat beli. Melalui hasil perhitungan yang telah dilakukan diperoleh nilai t-hitung $(8,304)$ lebih besar daripada t-tabel $(1,988)$ atau dapat dilihat dari nilai signifikansi $0,000<0,05$.

\section{Pengaruh Celebrity Endorser Terhadap Minat Beli Shampo Clear.}

$\mathrm{H} 2$ = Celebrity Endorser berpengaruh terhadap minat beli shampo Clear pada mahasiswa Universitas Sari Mutiara Indonesia. Dari hasil pengujian hipotesis (H2) yang 
dilakukan peneliti terbukti bahwa Celebrity Endorser shampo Clear memiliki pengaruh yang signifikan terhadap minat beli. Melalui hasil perhitungan yang telah dilakukan diperoleh nilai t-hitung $(5,204)$ lebih besar daripada t-tabel $(1,988)$ atau dapat dilihat dari nilai signifikansi $0,000<0,05$.

\section{Pengaruh harga dan celebrity endorser Terhadap minat beli shampo Clear.}

H3 = variabel harga dan celebrity endorser berpengaruh terhadap minat beli shampo Clear pada mahasiswa Universitas Sari Mutiara Indonesia. Dari pengujian variabel secara simultan dapat dilihat bahwa nilai $\mathrm{F}_{\text {hitung }}(117,184)>\mathrm{F}_{\text {tabel }}(3,090)$ atau sig. sebesar $=0,000<0,05$ dengan demikian $\mathrm{H} 0$ ditolak dan Ha diterima. Hal ini dapat disimpulkan bahwa variabel harga(X1) dan celebrity endorser(X2) berpengaruh positifdan signifikan terhadap minat beli (Y)shampo Clear pada mahasiswa Universitas Sari Mutiara Indonesia.

\section{Kesimpulan}

1. Harga berpengaruh secara signifikan terhadap minat beli dengan nilai signifikan variabel harga yaitu sig. sebesar 0,000 $<0,05$ dan nilai thitung sebesar $8.304>\mathrm{t}$-tabel 1,985 .

2. Celebrity endorser berpengaruh secara signifikan terhadapminat beli dengan nilai signifikan variabel celebrity endorser yaitu sig. sebesar $0,000<0,05$ dan nilai thitung sebesar $5.204>\mathrm{t}$-tabel 1,985.

3. Harga dan celebrityendorser berpengaruh secara signifikanterhadap minat beli dengan nilai $F_{\text {hitung }}(117,184)>\mathrm{F}_{\text {tabel }}(3,09)$ atau sig.sebesar $0,000<0,05$ dan nilai koefisien determinasi $\left(\mathrm{R}^{2}\right)$ yaitu sebesar 0.785 atau $78,5 \%$, dimana nilai koefisien determinasi ini menunjukkan bahwa hubungan antara harga dan celebrity endorser terhadap minat beli adalah tingkat kuat, sedangkan sisanya sebesar $21.5 \%$ dipengaruhi oleh variabel lain diluar penelitian ini.

\section{Daftar Pustaka}

Alkatiri, S., Tumbel, A. L., \& Roring, F. (2017). Pengaruh Daya Tarik Iklan Dan Potongan Harga Terhadap Minat Beli Konsumen Pada Matahari Departement Store Manado Town Square. Jurnal EMBA: Jurnal Riset Ekonomi, Manajemen, Bisnis dan Akuntansi, 5(2).

Fauzan, A., \& Rohman, A. (2019). PengaruhHarga Dan Kualitas ProdukTerhadap Minat Beli Sepeda Motor Kawasaki. Jurnal Ekonomi, Bisnis \&Manajemen, Vol.9. No.2.

Hardiyanti, G. P. (2020). Analisis Pengaruh Harga, Desain Produk, Citra Merek (Brand Image), Dan Bintang Iklan (Celebrity Endorser) Terhadap MinatBeli Kosmetik Focallure. Jurnal Sekolah Tinggi Ilmu EkonomiIndonesia, Hal. 1-19.

Pakaya, M. A., Oroh, S. G., \& Tumbuan, W. J. A. (2017). Pengaruh Harga Dan Kualitas Produk Terhadap Keputusan Pembelian Shampoo Clear Men Di Manado (Studi Kasus Mahasiswa Fakultas Ekonomi Dan Bisnis Universitas Samratulangi). Jurnal EMBA: Jurnal Riset Ekonomi, Manajemen, Bisnis dan Akuntansi, 5(2).

Sugiyono. (2014). Metode Penelitian Manajemen. Bandung: Alfabeta.

Sugiyono. (2017). Metode Penelitian Kuantitatif, Kualitatif, dan R\& D. Bandung: Alfabeta.

Suhardi, D., \& Irmayanti, R. (2019). Pengaruh celebrity endorser, citra merek, dan kepercayaan merek terhadap minat beli konsumen. Jurnal Inspirasi Bisnis Dan Manajemen, 3(1), 53-62.

Sukma, K. A. D. S. K., Nurcahya, I. K., \& Suryani, A. (2016). Pengaruh Celebrity Endorser, Brand Image dan Kepercayaan terhadap Keputusan Pembelian Produk Pembersih Wajah Men's Biore. Jurnal Manajemen Unud, Vol. 5, No.7, 4016-4043. 